\title{
Chromosomal Damage in Pigs from a Farm of Central Argentina
}

\author{
R. N. Genghini ${ }^{1}$, I. N. Tiranti ${ }^{1}$, P. A. Wittouck ${ }^{1}$, \\ J. C. De Luca ${ }^{2}$ and F. N. Dulout ${ }^{2}$ \\ ${ }^{1}$ Genética, Facultad de Agronomía y Veterinaria, Universidad Nacional de Río Cuarto. Río Cuarto, Argentina \\ ${ }^{2}$ CIGEBA, Facultad de Ciencias. Veterinarias, Universidad Nacional de la Plata. La Plata, Argentina
}

Accepted July 24, 1997

Chromosomal aberrations can spontaneously occur in low proportion in pigs, therefore, high frequencies indicate a possible exposure to genotoxic agents. It seems that an increase in chromosomal mutation rate has taken place, taking into account the prevalence of such agents in the general environment of swine populations. For this reason, Gustavsson (1990) advocated the urgent necessity to identify environmental mutagens and to verify their effect on pig health.

Chromosomal damage induced by radiation and also by chemical mutagens in swine has already been reported by different authors. McFee et al. (1970a, 1970b, 1971, 1972, 1973, 1974) studied chromosomal mutation rate in lymphocytes caused by neutrons and gamma rays. Fries and Strazinger (1982) analyzed the mutagenic effect in pigs derived from X-irradiated semen, having as a main consequence a decrease of litter size due to an induction of chromosomal translocations and inversions. Forster and Butler (1978) demonstrated an in vitro adverse effect of halothane on pig lymphocyte chromosomes.

Pig chromosomal damage induced by virus was reported by Lodja and Rubes (1977) who found that the Swine Fever lapinized live vaccine induced structural chromosomal aberrations as well as lymphocyte polyploidy on vaccinated pigs.

Rubes (1987) suggested the routine examination of lymphocyte chromosome to assess the environmental quality of pig farms which are exposed to pollution from different substances such as aflatoxin B1, biphenols, polychlorinates, DDT, lindane, mercury and cadmium. Rubes et al. (1992) used this analysis not only in pigs but also in other farm animals as a pollution-level indicator due to agricultural and industrial activities in the Czech Republic. About 3.6\% of pig lymphocytes showed chromosomal damage in highly contaminated farms of that country.

Several cases of chromosomal damage in pigs with reproductive problems from a farm located in Río Cuarto surroundings, an important swine production region of central Argentina, are reported in the present paper.

\section{Material and methods}

Cytogenetic analysis was performed in ten Duroc pigs from a farm located about $30 \mathrm{~km}$ away from Río Cuarto National University's campus, Córdoba Province, in central Argentina. Consultations resulted from a real necessity of farmers after having sudden reproductive problems: Last farrowings of sows which had previously given birth to normal size litters and then had begun to give birth to litters no bigger than three piglets each time. Two of those showed hindleg paralysis. One was sacrificed and sent to clinical observations. Adult animals had been recently vaccinated against Swine Fever virus; the region is endemic for Aujeszky disease.

In a first sampling, analyses in eight breeding pigs ( 7 sows and 1 boar) were performed; some

Address: Rosa N. Genghini, Genética, Fac. de Agron. y Vet., Universidad Nac. de Río Cuarto 5800 Río Cuarto, Argentina. 
months later, they were also done in a sow and its piglet. Since all animals were raised under similar farming management sharing the same type of environment, and therefore, they had been exposed to the same genotoxic agents, methodology control was made by using blood samples from three pigs of the same swine race which came from another farm. Those control animals presented a normal karyotype as it has been previously reported (Genghini et al. 1994). Lymphocyte cultures of both, affected and control animals, were done using the same batches of tissue culture materials when chromosome observation was being held.

Heparinized blood samples were obtained from auricular vein. Lymphocyte cultures were performed in TC199, since they give higher mitotic index than in RPMI medium. TC199 was supplemented with $10 \%$ calf serum plus bovine fetal serum, $1 \%$ glutamine, $1.5 \%$ cystine, $1 \%$ penicillinstreptomycin and phytohemagglutinin as mitogen. Cultures were incubated at $37^{\circ} \mathrm{C}$ for $72 \mathrm{hr}$ and treated with colchicine $(0.05 \mu \mathrm{g} / \mathrm{ml})$ for $30 \mathrm{~min}$ before fixation. Air dried slides were made after hypotonic treatment and fixation with methanol-acetic acid $3: 1$.

Preparations were stained with Giemsa for aberration counting. Chromosome identification was made according to the Standard International Karyotype for pigs (Committee 1988) by means of GTG-banding using Seabright's technique (1971). About 100 metaphases per animal were scored blind.

Viral agents in macerated organs of an affected sow were searched. Samples of lungs, spleen, liver, tonsils, maxilar and suprahepatic ganglia were observed. Monolayers of Vero cells were infected with those organs looking for cytopathic effect of Aujeszky virus; the sow's serum was used to detect antiviral antibodies of Aujeszky disease by means of microserumneutralization.

\section{Results}

Cytogenetic results from the first sampling are shown in Table 1. The eight tested pigs from the first sampling showed a high incidence of chromosomal damage including chromatid and chromosome breaks, chromatid exchanges (triradial and quadriradial configurations) and even meta-

Table 1. Frequency of chromosome aberrations observed in hypoprolific and normal pigs

\begin{tabular}{|c|c|c|c|c|c|c|c|c|}
\hline \multirow{2}{*}{$\begin{array}{c}\text { Animal } \\
\mathrm{N}^{\mathrm{o}}\end{array}$} & \multirow{2}{*}{$\begin{array}{l}\text { Number of } \\
\text { cells scored }\end{array}$} & \multirow{2}{*}{$\begin{array}{c}\text { Abnormal } \\
\text { metaphase } \\
\text { per } 100 \text { cells }\end{array}$} & \multicolumn{6}{|c|}{ Chromosomal aberrations per 100 cells } \\
\hline & & & $\mathrm{AL}$ & $\mathrm{B}^{\prime}$ & $\mathrm{B}^{\prime \prime}$ & $\mathrm{RB}^{\prime}$ & FRG & MA \\
\hline \multicolumn{9}{|l|}{ Controls } \\
\hline 1 & 100 & - & 1.0 & - & - & - & - & - \\
\hline 2 & 95 & - & 1.1 & - & - & - & - & - \\
\hline 3 & 100 & - & 2.0 & - & - & - & - & - \\
\hline All controls & 295 & - & 1.4 & - & - & - & - & - \\
\hline \multicolumn{9}{|l|}{ Hypoprolific pigs } \\
\hline 1 & 102 & 24 & 8.8 & 5.9 & 9.8 & 0.9 & 4.9 & 3.9 \\
\hline 2 & 100 & 20 & 5.0 & 9.0 & 5.0 & 1.0 & 6.0 & 2.0 \\
\hline 3 & 114 & 19 & 9.6 & 7.9 & 3.5 & 3.5 & 2.6 & 1.7 \\
\hline 4 & 106 & 21 & 11.3 & 10.3 & 1.9 & 1.9 & 5.6 & 2.8 \\
\hline 5 & 100 & 29 & 8.0 & 9.0 & 7.0 & 3.0 & 9.0 & 2.0 \\
\hline 6 & 97 & 25 & 14.4 & 13.4 & 2.1 & 1.0 & 6.2 & 4.1 \\
\hline 7 & 100 & 19 & 8.0 & 6.0 & 3.0 & 2.0 & 7.0 & 3.0 \\
\hline 8 & 99 & 32 & 9.1 & 11.1 & 7.1 & 3.0 & 8.1 & 6.1 \\
\hline All hypoprolific pigs & 818 & 23.5 & 9.0 & 9.0 & 4.9 & 2.1 & 6.1 & 3.2 \\
\hline
\end{tabular}

Abnormal cells, cell with at least one chromosomal aberration. Cell which only had achromatic lesions were not scored as abnormal. AL, achromatic lesions (gaps); B', chromatid break; B", isochromatid or chromosome break; RB', chromatid exchange; FRG, fragment; MA, multiple abnormalities. 


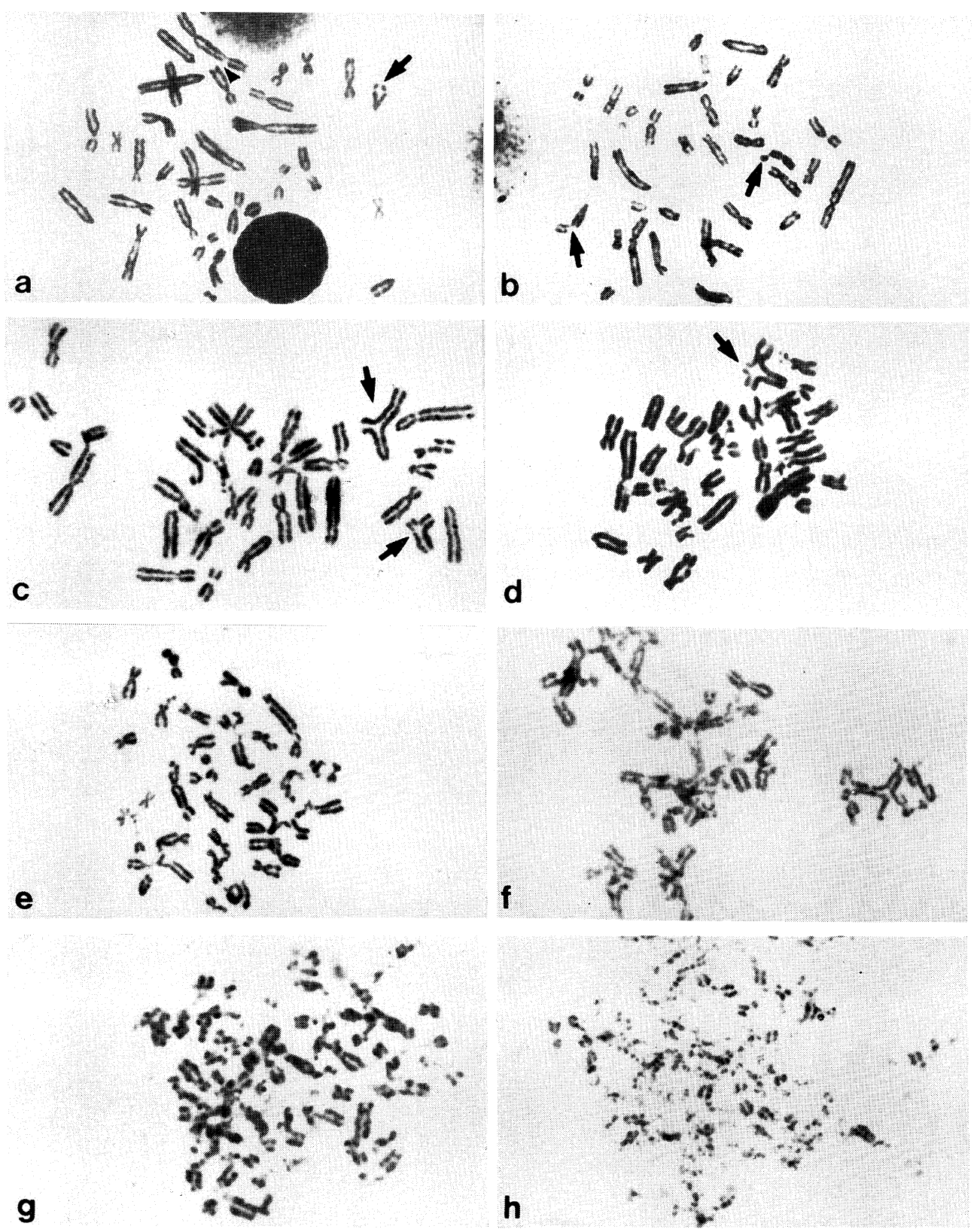

Fig. 1. Pig chromosomes with several types of aberrations. a) isochromatid gap (arrow), monochromatid break (arrow-head), b) fragments (arrows), c) trirradials (arrows), d) quadrirradial (arrows), e) and f) multiple abnormalities, g) and h) different expressions of chromosome pulverization.

phases with multiple aberrations (Figs. 1a-f). The frequency of abnormal cells (from one cromatid break to multiple abnormalities) ranged from 19 to $32 \%$. The highest frequency was found in a sow with hindquarter paralysis. Blood samples taken from control animals gave normal karyotype, presenting monochromatid gaps in only $1.4 \%$ of the cells, that percentage is considered the basal damage value in this study.

Chromosomal pulverization, as defined by Savage (1976) was observed (Figs. 1g, h). This abnormality was not recorded individually for the first eight animals tested. Cells with pulverization 


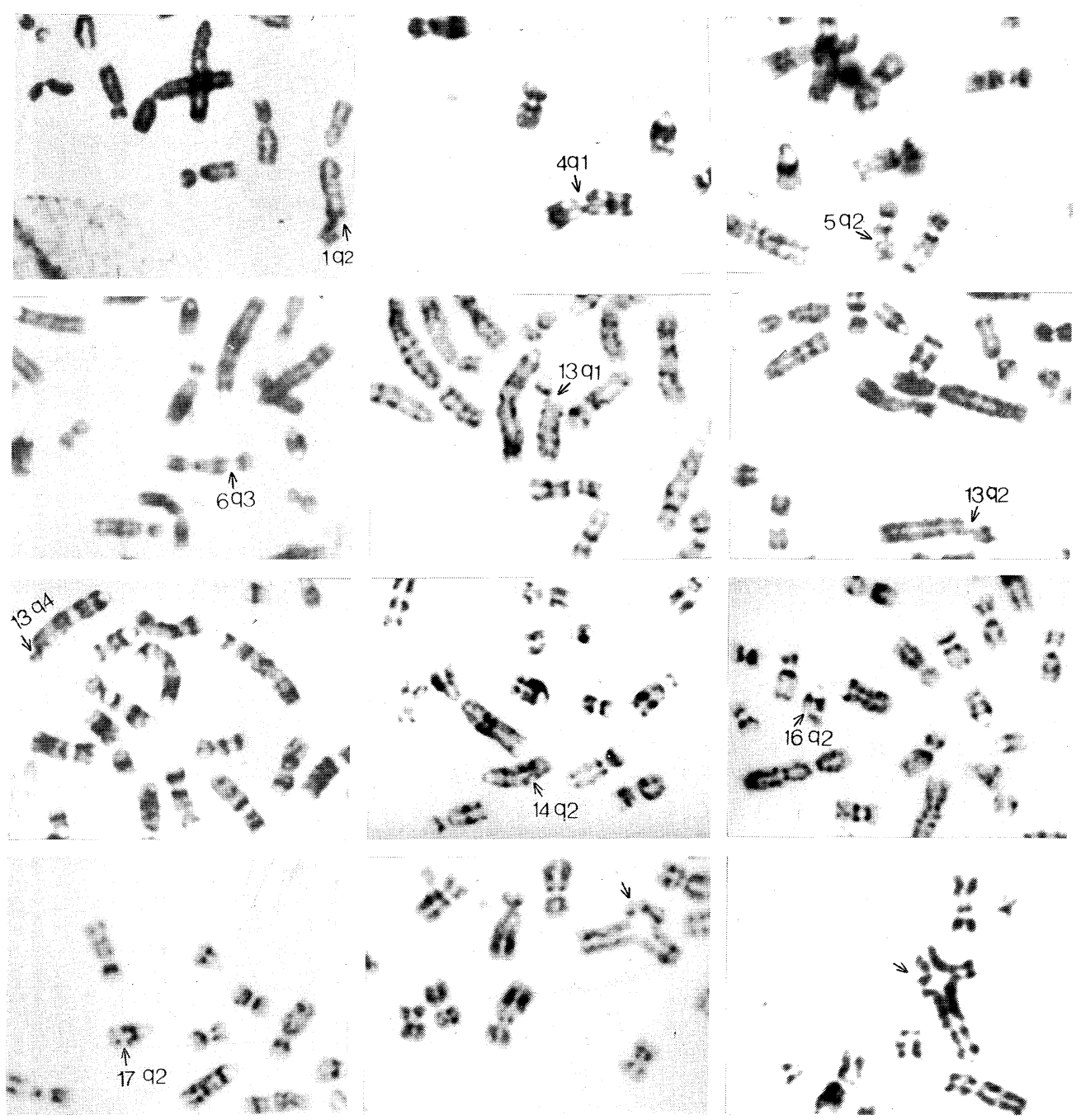

Fig. 2. Pig GTG-banded chromosome showing different breakage regions (arrows).

Table 2. Chromosome regions with breaking points revealed with GTG-banding

\begin{tabular}{cc}
\hline \hline Chromosome regions & $\%$ Cells \\
\hline $1 \mathrm{q} 2$ & 20 \\
$4 \mathrm{q} 1$ & 6 \\
$5 \mathrm{q} 2$ & 3 \\
$6 \mathrm{q} 3$ & 6 \\
$13 \mathrm{q} 1$ & 6 \\
$13 \mathrm{q} 2$ & 23 \\
$13 \mathrm{q} 4$ & 13 \\
$14 \mathrm{q} 2$ & 6 \\
$16 \mathrm{q} 2$ & 6 \\
$17 \mathrm{q} 2$ & 3 \\
\hline
\end{tabular}

reached a proportion of $15 \%$ when considering all these animals in bulk. An average of $80 \%$ of cells showed pulverized chromosomes in the sow and its only surviving piglet from the second sampling, as the only chromosomal aberration type recorded in these two animals.

The analysis by GTG-banding of cells with chromosome alterations evidenced that chromosome breakage mainly appeared in ten regions of eight chromosomes (Table 2, Fig. 2). Chromosome 13, the longest telocentric, and therefore easily identifiable without banding, showed the highest aberration frequency, with 
breaks located mostly at q2 and q4 regions in $36.6 \%$ of cells. Breaks in 1q2 were detected in a lower proportion ( $20 \%$ of cells). Aberrations in other chromosomes happened in 3 to $6 \%$ of cells.

Clinical studies of the sacrificed sow as well as macroscopic analyses of several organs were within normal limits. There were no detectable effects for Aujeszky virus in macerated organs; although the hepatic suspension produced morphological alterations by modifying the Vero cell monolayers in a way non compatible with the typical cytopathic effect of Herpes Virus family to which Aujeszky virus belongs to.

\section{Discussion}

Pigs with reproductive impairment showed a high frequency of chromosomal damage in peripheral blood lymphocytes. However, as chromosomal aberrations were unstable and mainly of the chromatid type, it is not possible to assert that hypoprolificity was a direct consequence of the cytogenetic damage observed. A more reasonable interpretation could be given by inferring that both chromosomal damage and hypoprolificity are more likely to be originated by the same etiologic agent. This assumption is supported by the fact that hypoprolificity appeared in a sudden way in the farm.

The type and extent of chromosomal damage could be a virus infection indicator. It is well known that most virus assayed either in vivo or in vitro tests show clastogenic properties (Nichols et al. 1962, 1964, Stich et al. 1964, Stich and Yohn 1970, Krut 1974, Soldadovic et al. 1981, Dulout et al. 1983, 1985). Moreover, viral vaccines seem to have a similar effect, however, no conclusive results on this topic have been reported (Nichols 1963, Harnden 1964, Aula 1965, Lodja and Rubes 1977). The hypothesis of viral infection is supported by the occurrence of chromosome pulverization which is originated after cell fusion induced by certain virus promoting syncytium formation, according to Johnson and Rao (1970). When no syncytia induction occurs, this should be due to a degradation of condensed chromatin as a result of the virus infection, as observed by Stich et al. (1964) for Herpes and by Nichols et al. $(1964,1965)$ for Measles viruses.

The higher incidence of breaks found in chromosomes 13 and 1 was probably related to their inherent size. Breaking points, except for 13q1, are coincident with the well known reciprocal translocation points associated with fragile sites (Yang and Long 1993, Rigg et al. 1993).

The existence of two animals affected with hindleg paralysis would suggest the presence of some pollutant with genotoxic effects in the farm where samples were taken. This would support Long's observation (1991) that there are some chromosome damaging factors within the pig environment which would explain the origin of breaks producing reciprocal translocations. Such agents could be drugs, chemicals and pathogenic organisms which might be present in pig farms; although some kind of environmental stress cannot be excluded.

We believe that the chromosomal damage found in our material was induced by some genotoxic agent which affected the animals of the surveyed farm. Due to the prevalence of chromosome pulverization in the cytogenetically sampled animals, the most probable clastogenic agent might be a virus. However, further investigations are necessary before any definitive conclusion can be reached.

\section{Summary}

Cytogenetic analysis of peripheral blood lymphocytes was carried out in ten hypoprolific pigs from a farm located near Río Cuarto National University, where sows gave birth to no more than three piglets in their later farrows.

Blood samples from seven sows and one boar were obtained in a first instance. Animals showed a high frequency of chromosomal abnormalities (ranging from 19 to 32 per 100 cells 
scored). Chromosomal aberrations were mainly chromatid breaks, chromatid exchanges (triradials, quadriradials) and chromosome fragments. In addition, $15 \%$ of the metaphases showed chromosomal pulverization. A sow and its piglet were studied in a second sampling detecting only chromosome pulverization aberration type ( $80 \%$ of the cells scored in average). Chromosomal localization of breaks was done with GTG banded metaphases. At least, eight chromosomes were involved, the highest frequency of breaks was located in the longest telocentric (chromosome $\mathrm{n}^{\circ} 13$ ). "Chromosome pulverization" has been associated to virus infection. All studied adult animals were vaccinated against Swine Fever, Aujeszky disease is endemic for the region. Consequently, chromosomal damage could be induced by subclinical viral infection. Chromosomal anomalies might be related to the reproductive impairment of pigs; however, further studies would be necessary to identify the clastogenic agent.

Key words : Pig cytogenetics, Chromosomal aberrations, Clastogenic agents.

\section{Acknowledgements}

Clinical analysis was made by Dr. A. Larriestra. Virological tests by Dr. L. Sabini and Mr. G. Aimar assisted us in the field work. Our gratitude to all of them.

\section{References}

Aula, P. 1965. Virus associated chromosome breakage. A cytogenetic study of chickenpox, measles, and mumps patients and of cell cultures inected with measles virus. Ann. Acad. Sci. Fenn, ser. A 89: 1-75.

Committee for the Standardized Karyotype of the Domestic Pig. 1988. Standard Karyotype of the domestic pig. Hereditas 109: $151-157$.

Dulout, F. N., Carballal, G., Bianchi, N. and von Guradze, H. N. 1983. Cytogenetic effect of two strains of Junin Virus in the Guinea Pig. Intervirology 19: 44-46.

—, Panissee, H. E., Carballal, G., von Guradze, H. N., De Luca, J. C., Oubiña, J. R. and Videla, C. 1985. Junin Virus-Induced chromosomal aberrations in the Guinea Pig. Intervirology 24: 193-198.

Forster, M. and Butler, I. 1978. Mutagenic effects of Halothane. I. Chromosome aberrations of in vitro treated pig lymphocytes. Z. Tierzuchtg. Zuchgsbiol. 95: 306-309.

Fries, R. and Strazinger, G. 1982. Chromosomal mutations in pigs derived from X-irradiated semen. Cytogenet. Cell Genet. 34: 55-56.

Genghini, R., Wittouck, P., Tiranti, I. and Bonvillani, A. 1994. Desarrollo de un procedimiento citogenético para el estudio de cerdos con problemas reproductivos. Rev. UNRC 14(1): 79-90.

Gustavsson, I. 1990. Chromosomes of the pig. Advances in veterinary science and comparative medicine. 34: 73-107.

Harnden, D. G. 1964. Cytogenetic studies in patients with virus infection and subjects vaccinated against yellow fever. Am. J. Hum. Genet. 16: 204-213.

Johnson, R. T. and Rao, P. N. 1970. Mammalian cell fusion: Induction of premature chromosome condensation in interphase nuclei. Nature 226: 717-722.

Krut, N. 1974. Chromosome anomalies induced by swine fever virus. Veterinariya, Moscow 4: 55-56.

Lodja, L. and Rubes, J. 1977. Chromosome aberrations in pigs after vaccination with living vaccine against swine fever. Ann. Genet. Sel. Anim. 9: 540.

Long, S. E. 1991. Reciprocal translocations in the pig (Sus scrofa): a review. Veterinary Record 128: 275-278.

McFee, A. F., Banner, M. W. and Sherrill, M. N. 1970a. Influence of animal age on radiation-induced chromosome aberrations in swine leukocytes. Radiation Research 41: 425-435.

- - - and - 1970b. Chromosome aberrations in swine leukocytes after in vivo or in vitro exposure to $14 \mathrm{MeV}$ Neutrons. Radiation Research 44: 512-522.

- - - and - 1971. Behaviour of swine leukocytes in culture after in vivo or in vitro exposure to $14 \mathrm{MeV}$ Neutrons. Radiation Research 48: 346-357.

- , - - - and Milhes, J. B. 1972. Disappearance rates of radiation-induced chromosome aberrations from swine leukocytes. Mutation Research 15: 325-330.

-, Sherrill, M. N. and Banner, M. W. 1973. Radiation-induced aberrations in aneuploid vs. diploid swine leukocytes. Mutation Research 18: 311-314. 
—, Banner, M. W. and Sherrill, M. N. 1974. Chromosome aberrations in the leukocytes of partial-body and whole-body irradiated swine. Radiation Research 60: 165-172.

Nichols, W. W. 1963. Relationships of viruses, chromosomes and carcinogenesis. Hereditas 50: 53-80.

—, Levan, A., Hall, B. and Östergren, G. 1962. Measles-associated chromosome breakage. Hereditas 48: 367-370.

-, -, Aula, P. and Norrby, E. 1964. Extreme chromosome breakage induced by measles virus in different in vitro systems. Hereditas 51: 380-382.

- - Pertti, A. and Norrby, E. 1965. Chromosome damage associated with measles virus in vitro. Hereditas 54: 101-118.

Riggs, P. K., Kuczek, T., Chrisman, C. L. and Bidwell, C. A. 1993. Analysis of aphidicolin-induced chromosome fragility in the domestic pig (Sus scrofa). Cytogenet. Cell Genet. 62: 110-116.

Rubes, J. 1987. Chromosomal aberrations and sister-chromatid exchange in swine. Mutation Research 191: $105-109$.

—, Borkovec, L., Horinova, Z., Urbanova, J., Prokova, I. and Kulikova, L. 1992. Cytogenetic monitoring of farm animals under conditions of environmental pollution. Mutation Research 283: 199-210.

Savage, J. P. K. 1976. Classification and relationships of induced chromosomal structural changes. Journal of Medical Genetics 13: 103-122.

Seabright, M. 1971. A rapid technique for human chromosome. Lancet 2: 971-972.

Soldatovic, B., Zimonijic, D., Haidary, M. A. N. and Cvetkovic, M. 1981. Chromosomal set changes in domestic swine caused by the swine fever virus. Acta Veterinaria, Yugoslavia 31: 27-33.

Stich, H. F., Hsu, T. C. and Rapp, F. 1964. Viruses and mammalian chromosomes. I. Localization of chromosome aberrations after infection with Herpes Simplex Virus. Virology 22: 439-445.

— and Yohn, D. S. 1970. Viruses and chromosomes. Prog. med. Virol. Vol. 12, pp. 78-127 (Karger. Basel).

Yang, M. Y. and Long, S. E. 1993. Folate sensitive common fragile sites in chromosomes of the domestic pig (Sus scrofa). Research in Veterinary Science 55: 231-235. 